\title{
Model predictive control applied to a heating system with PV panels and thermal energy storage
}

\author{
Joan Tarragona ${ }^{1,2}$, Cèsar Fernández ${ }^{1}$, Luisa F. Cabeza ${ }^{1}$, Alvaro de Gracia ${ }^{1,2, *}$ \\ ${ }^{1}$ GREiA Research Group, INSPIRES Research Centre, University of Lleida, Lleida, Spain \\ ${ }^{2}$ CIRIAF - Interuniversity Research Centre, University of Perugia, Perugia, Italy
}

\begin{abstract}
Nowadays, a considerable amount of energy is consumed by the building sector, especially due to space heating purposes. The overall cost of this energy demand can be reduced with the use of renewable energy sources. However, the main challenge to overcome is the mismatch between the power generation from renewables and the users demand. To tackle this issue, the main objective of the present study is to optimize the performance of a single-family house heating system based on an air-to-water heat pump, with thermal energy storage (TES) and PV panels, controlled through a model predictive control (MPC) strategy to minimize the final energy cost. Results obtained from several simulated cases point out that using this system, cost savings about $50 \%$ might be achieved. The analysis the impact of the TES system and PV panels in the heating operation together with a study of different working horizons and MPC settings are the novelties of this study.
\end{abstract}

\section{Introduction}

The climate change became a global problem, since during the last decades the raise of the world average temperature and the amount of carbon taxes increased until worrying levels. Therefore, the Paris COP21 agreement IEA (2016a) established that as long-term goal, the increasing of the world average temperature has to be maintained below $2{ }^{\circ} \mathrm{C}$ compared to pre-industrial levels. According to the IEA (2016b) one of the main energy consumers is the building sector and a better quality of life coupled with the higher number of housing drove this sector to consume over $30 \%$ of total final energy.

To take advantage of renewable energy resources is one of the key points to achieve the global energy targets. Currently, the world share of renewable energy accounts for $20 \%$ of the power and heat generation IEA (2016c), which represents $12 \%$ of the total in the building sector. Thus, to exploit the high potential of resources such as solar energy is a way to increase the share of renewables. However, the mismatch in the time period between the energy production and the peak load periods makes difficult its use. Accordingly, to find a system that is able to store energy for a large period of time is mandatory.

Regarding to this issue, thermal energy storage (TES) systems give to the user the chance to match in time the energy production with its consumption. The TES system acts as energy buffer, storing energy when there is solar availability and delivering it during on-peak hours.
Additionally, to go further in maximizing the efficiency of the system and hence to justify the initial investment, a smart control strategy to manage the whole heating operation has to be included to reach the full potential of TES systems (Yu et al., 2015).

To optimize the design parameters of the TES system, the right combination of technologies and size of the components based on weather and expected energy demand profiles for the site must be considered (Dincer et al., 2014). Once all the physical parameters are dimensioned, the second step is to define the control strategy.

Important advances in optimization and control heating and cooling systems were explored and tested during the last years. Afram and Janabi-Sharifi (2014) classified the heating, ventilation and air conditioning (HVAC) control methods in five big categories: classical control, soft control, hard control, hybrid control, and other control techniques. Within the hard control category, one of the most used and effective strategies to work in heating installations with TES systems was model predictive control (MPC). Concerning that, Thieblemont et al. (2017) proved that MPC had an increasing tendency in number of scientific publications in the last decade for single buildings with TES.

To check the potential of MPC as well, Oldewurtel et al. (2012) carried out tests with combinations of different buildings, HVAC equipment, and weather conditions. It was demonstrated that there were significant potential energy savings. More studies related with the application of MPC in different buildings may be found in the literature (Alimohammadisagvand et al., 2016; Salakij et al., 2016; Candanedo et al., 2013; Avci et al., 2013) and all of them conclude that running simulations with a proper working horizon, an acceptable data time step, and a correct modelling of the system provide important economic savings compared to the standard set-ups with ON/OFF control.

A set-up with PV panels, a heat pump, an electrical battery, slab cooling, and also an electric water heater was optimized by Vrettos et al. (2013) through a MPC strategy, using an hourly time step and a prediction horizon of 16 hours. The authors determined that higher horizons did not provide significant savings. Continuing with this approach, Gholamibozanjani et al. (2018) simulated a system with a solar air collector, a heat exchanger filled with a phase change material (PCM), a 
backup heater, and a couple of fans to move the air through the installation. This configuration was studied for three different schedules: domestic, office, and service. Also different settings of the MPC were studied. Authors conclusions confirmed that the utilization of the greater prediction horizon gave higher cost savings.

To the best of our knowledge, in the literature there are no studies considering strategies that combine both challenges controlling a heating system and optimizing its operation with TES, PV panels, and a time-of-use tariff structure, therefore, this is the main objective of this paper.

The proposed system is composed by PV panels, a water TES tank, an air-to-water heat pump (HP), and radiant floor. Also, the system will be grid-connected based on Spanish time-of-use tariff structure. Emphasizing the high potential of coupling MPC and TES for a single family house heating system, this paper studies different settings of MPC for a continental weather at simulation level. The ability of the control strategy to forecast future weather conditions, storing the surplus of energy during solar hours, and using the grid as less as possible throughout the on-peak period will be effectively analysed in the next sections.

\section{Methodology}

In this section, an overview upon the studied system, the MPC model used to control the heating operation, and the analysed case studies are described in detail.

\section{System}

The simulated system was composed by the elements shown in Figure 1, with the specific role described next.

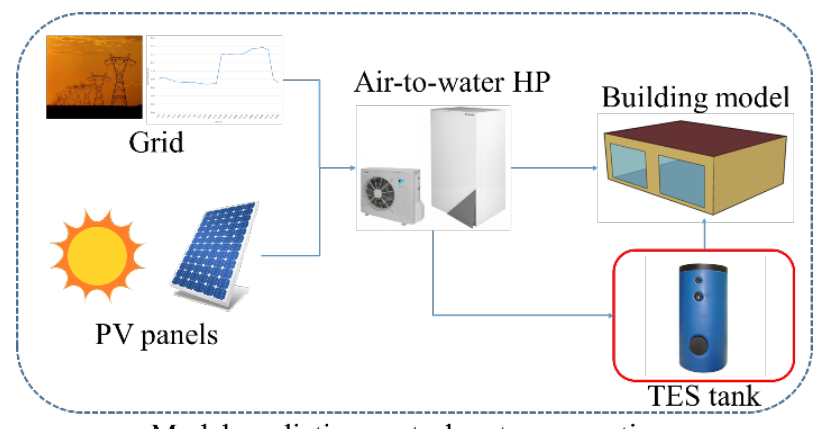

Model predictive control system operation

Figure 1: System operation scheme.

\section{Air-to-water HP}

The air-to-water HP transforms the electricity absorbed by the PV panels and purchases from the grid to thermal energy. Then, this thermal energy can be delivered from the HP in three different ways: directly to the building, straight to the water TES tank, or splitting the flow between them. The simulated HP had a Coefficient of Performance (COP) variable as a function of the outdoor temperature (Eq. 1):

$$
\operatorname{COP}\left(\mathrm{T}_{\text {out }}\right)=0.0005 \cdot \mathrm{T}_{\text {out }}{ }^{2}+0.0756 \cdot \mathrm{T}_{\text {out }}+2.2216 \quad \text { (Eq. 1) }
$$

PV panels

The numerical model takes into account the area of two PV panels with a surface of $1.64 \mathrm{~m}^{2}$ each. The used solar radiation data was obtained from a continental climate. Additionally, there was a logic gate, controlling the operation of PV panels that defined whether the panels worked or not.

\section{Electricity from the grid}

The electricity price scheme used in this study is based on the time-of-use tariff structures available in the electricity Spanish market. The chosen tariff was the two periods 2.0 DHA, in which the off-peak time is from 10 pm to 12 am and the on-peak the rest of the day, during winter time. All the price data was directly imported from the Red Eléctrica de España (retrieved from www.ree.es) for all the simulated period.

\section{Water TES tank}

Focusing in the storage system, the employed water TES tank was the Lapesa G-140-IF. All the tank features were described in Table 1. The main goals of this element were to store energy during the off-peak hours and to store the excess solar energy to be consumed at night.

Table 1: Characteristics of the water TES tank.

\begin{tabular}{|c|c|}
\hline Capacity [L] & 140 \\
\hline External diameter [mm] & 480 \\
\hline Overall height [mm] & 1155 \\
\hline Thermal conductivity (with insulation) $\left[\mathrm{W} / \mathrm{m}^{\cdot}{ }^{\circ} \mathrm{C}\right]$ & 0.025 \\
\hline Insulation thickness [mm] & 40 \\
\hline
\end{tabular}

\section{Building model}

EnergyPlus software was used to achieve the heating demand profile for a single family house. The BESTEST Case 900 (American Society of Heating, Refrigerating and Air-Conditioning Engineers (2011)) was taken into account as building model, since the materials and type of construction were similar to Spain common buildings (Figure 2).

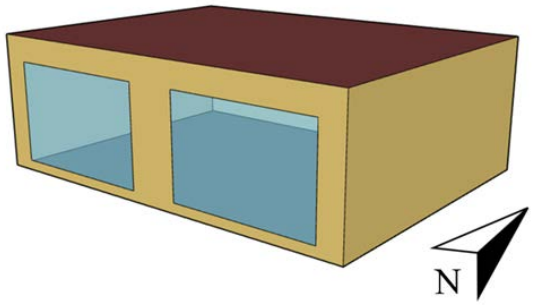

Figure 2: Scheme of EnergyPlus simulated building.

The simulations were carried out with a time step of 5 minutes using the weather conditions of Puigverd de Lleida (Spain). The building had two windows (6 $\mathrm{m} 2$ of surface each) exposed to south and the three remaining walls did not have any opening. There were no partitions 
inside, being a diaphanous space. Regarding the main construction characteristics, the wall materials are shown in Table 2. The whole building had a high mass construction and this is verified also in Table 3, where the layers of the floor are specified. In addition, the roof is defined in Table 4 and the properties of the windows are shown in Table 5.

Table 2: Wall construction of the base case building.

\begin{tabular}{|c|c|c|c|}
\hline Element & $k(W / m \cdot K)$ & Thick. (m) & $\mathbf{R}\left(\mathbf{m}^{2} \cdot \mathbf{K} / \mathbf{W}\right)$ \\
\hline $\begin{array}{l}\text { Int. surface } \\
\text { coeff. }\end{array}$ & & & 0.121 \\
\hline $\begin{array}{c}\text { Concrete } \\
\text { block }\end{array}$ & 0.510 & 0.100 & 0.196 \\
\hline $\begin{array}{c}\text { Foam } \\
\text { insulation }\end{array}$ & 0.040 & 0.0615 & 1.537 \\
\hline Wood siding & 0.140 & 0.009 & 0.064 \\
\hline $\begin{array}{l}\text { Ext. surface } \\
\text { coeff. }\end{array}$ & & & 0.034 \\
\hline $\begin{array}{l}\text { Overall, air- } \\
\text { to-air }\end{array}$ & & & 1.952 \\
\hline
\end{tabular}

The composition of the simulated building was similar to the local architecture with the main challenge to maintain the heat inside and to protect against the inclement weather of the external environment.

Table 3: Floor construction of the case building.

\begin{tabular}{|c|c|c|c|}
\hline Element & $\mathbf{k}(\mathbf{W} / \mathbf{m} \cdot \mathbf{K})$ & Thick. $(\mathbf{m})$ & $\mathbf{R}\left(\mathbf{m}^{2} \cdot \mathbf{K} / \mathbf{W}\right)$ \\
\hline $\begin{array}{c}\text { Int. surface } \\
\text { coeff. }\end{array}$ & 1.130 & 0.080 & 0.121 \\
\hline $\begin{array}{c}\text { Concrete } \\
\text { slab }\end{array}$ & 0.040 & 1.007 & 0.071 \\
\hline Insulation & & 25.175 \\
\hline $\begin{array}{c}\text { Overall, air- } \\
\text { to-air }\end{array}$ & & 25.366 \\
\hline
\end{tabular}

Table 4: Roof construction of the base case building.

\begin{tabular}{|c|c|c|c|}
\hline Element & $\mathbf{k} \mathbf{( W / m} \cdot \mathbf{K})$ & Thick. $(\mathbf{m})$ & $\left.\mathbf{R} \mathbf{~ ( m}^{2} \cdot \mathbf{K} / \mathbf{W}\right)$ \\
\hline $\begin{array}{c}\text { Int. surface } \\
\text { coeff. }\end{array}$ & 0.160 & 0.010 & 0.121 \\
\hline Plasterboard & 0.040 & 0.1118 & 2.794 \\
\hline $\begin{array}{c}\text { Fiberglass } \\
\text { quilt }\end{array}$ & 0.140 & 0.019 & 0.136 \\
\hline Roof deck & & & 0.034 \\
\hline $\begin{array}{c}\text { Ext. surface } \\
\text { coeff. }\end{array}$ & & 3.147 \\
\hline $\begin{array}{c}\text { Overall, air- } \\
\text { to-air }\end{array}$ & & & \\
\hline
\end{tabular}

Table 5: Window properties of the base case building.

\begin{tabular}{|c|c|}
\hline Extinction coefficient & $0.0196 / \mathrm{mm}$ \\
\hline Number of panes & 2 \\
\hline Pane thickness & $3.175 \mathrm{~mm}$ \\
\hline Air-gap thickness & $13 \mathrm{~mm}$ \\
\hline Index of refraction & 1.526 \\
\hline $\begin{array}{l}\text { Normal direct-beam transmittance } \\
\text { through one pane }\end{array}$ & 0.86156 \\
\hline Thermal conductivity of glass & $1.06 \mathrm{~W} / \mathrm{m} \cdot \mathrm{K}$ \\
\hline Conductance of each glass pane & $33 \mathrm{~W} / \mathrm{m}^{2} \cdot \mathrm{K}$ \\
\hline $\begin{array}{l}\text { Combined radiative and convective } \\
\text { coefficient of air gap }\end{array}$ & $6.297 \mathrm{~W} / \mathrm{m}^{2} \cdot \mathrm{K}$ \\
\hline Exterior combined surface coefficient & $21.00 \mathrm{~W} / \mathrm{m}^{2} \cdot \mathrm{K}$ \\
\hline Interior combined surface coefficient & $8.29 \mathrm{~W} / \mathrm{m}^{2} \cdot \mathrm{K}$ \\
\hline U-value from interior air to ambient air & $3.0 \mathrm{~W} / \mathrm{m}^{2} \cdot \mathrm{K}$ \\
\hline $\begin{array}{l}\text { Hemispherical infrared emittance of } \\
\text { ordinary uncoated glass }\end{array}$ & 0.9 \\
\hline Density of glass & $2500 \mathrm{~kg} / \mathrm{m}^{3}$ \\
\hline Specific heat of glass & $750 \mathrm{~J} / \mathrm{kg} \cdot \mathrm{K}$ \\
\hline Interior shade devices & None \\
\hline $\begin{array}{c}\text { Double-pane shading coefficient at } \\
\text { normal incidence }\end{array}$ & 0.907 \\
\hline $\begin{array}{l}\text { Double-pane solar heat gain coefficient } \\
\text { at normal incidence }\end{array}$ & 0.789 \\
\hline
\end{tabular}

Other than the materials characterization, this Case 900 had a series of parameters that were already defined for the casuistic itself. They are the following:

- Infiltration $=0.5$ air change/hour.

- Internal load $=200 \mathrm{~W}$ continuous, $60 \%$ radiative, $40 \%$ convective, $100 \%$ sensible.

- Mechanical system $=100 \%$ convective air system, $100 \%$ efficient with no duct losses and no capacity limitation, no latent heat extraction, nonproportional-type dual set point thermostat with deadband.

- Soil temperature $=10^{\circ} \mathrm{C}$ continuous.

To include the heating operation to a single family house behaviour, a domestic schedule with a significant difference in the set point temperatures was programmed. Tables 6 and 7 show the weekdays and weekends set point schedules, respectively.

Table 6: Weekdays heating set point schedule.

\begin{tabular}{|c|c|c|}
\hline \multicolumn{3}{|c|}{ Weekdays } \\
\hline Description & Heating schedule & Set point $\left[{ }^{\circ} \mathbf{C}\right]$ \\
\hline Unoccupied period & From 9 am to 6 pm & 18 \\
\hline Occupied period & From 6 pm to 9 am & 22 \\
\hline
\end{tabular}


On one hand, for weekdays there was a distinction between occupied and unoccupied hours. The set point during the period with people at home was $22{ }^{\circ} \mathrm{C}$. Otherwise, the set point was reduced till $18{ }^{\circ} \mathrm{C}$ for the hours when the occupants are out.

Table 7: Weekends heating set point schedule.

\begin{tabular}{|c|c|c|}
\hline \multicolumn{3}{|c|}{ Weekends } \\
\hline Description & Heating schedule & Set point $\left[{ }^{\circ} \mathbf{C}\right]$ \\
\hline Night time & From 12 am to 6 am & 20 \\
\hline Day time & From 6 am to 12 am & 22 \\
\hline
\end{tabular}

On the other hand, during weekends, the difference was between night and day time. All day the temperature was $22{ }^{\circ} \mathrm{C}$, but during the night the set point decreased to $20^{\circ} \mathrm{C}$.

\section{Model predictive control}

A decision process optimized by a MPC strategy is based on formulating an optimization problem according to an objective function. Such problem is solved, taking into account a decision time step and a rolling prediction horizon. In the context of buildings, MPC predicted and optimized energy utilization and operating cost, subject to disturbances such as changes in energy prices, occupancy, and weather (Touretzky and Baldea, 2014).

Following up on this, the objective function of the present study was to reduce electricity costs using a MPC strategy. Thereby, the following data were taken for every time step: PV production, electricity price, heating demand, TES tank status, and outdoor temperature. Once all of them were obtained, MPC analysed and calculated the energy fluxes delivered from the HP either to the TES tank or to the building, and the amount of energy transferred from the tank to the building. Also, the MPC strategy gave the electricity flux taken from both PV panels and grid. A scheme of all the input and output fluxes is shown in Figure 3.

The main challenge of the presented MPC problem was to optimize all the energy and demanded fluxes shown in Figure 3, as a function of the electricity cost reduction. In this study, such optimization was designed as a mixed integer non-linear programming (MINLP) problem. Thereby, to obtain the final solution, different algorithmic techniques were available. To tackle this optimization problem, branch-and-bound algorithm was selected, due to its capacity to work with non-linearities and thus, to its suitability for such MINLP problem. Moreover, in this work the solving constraint integer programs (SCIP) solver (Achterberg, 2009) was used together with Python. With this election a fast and free tool to obtain the optimized final cost was created. Regarding to the operation of branch-and-bound, this type of algorithm analysed the candidate solutions, searching the optimal cost among all the possibilities. Once it detected a pointless node, the algorithm itself bounded such region. This process was repeated for the whole branchpossibilities until to achieve the optimal cost for every time step.

To further elaborate the knowledge of the MPC features used in the heating system, the parameters and the variables that define the MPC problem of this work are shown in Tables 8 and 9 respectively.

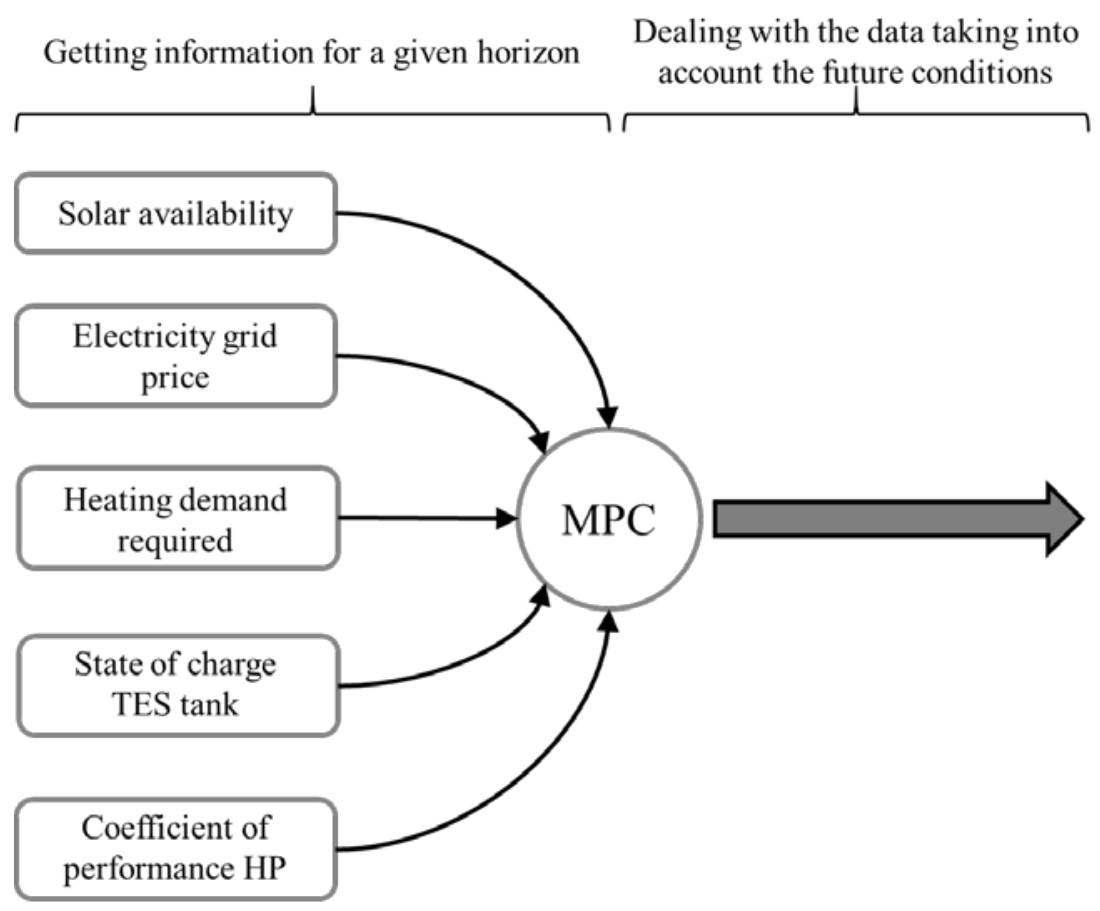

Energy input flux

Energy flux needed from the grid

Energy flux from the PV panels

\section{Demanded flux}

Energy from the HP to the demand

Energy from the HP to the TES tank

Energy from the TES tank to the demand

Figure 3: Energy fluxes managed by MPC controller. 
Table 8: Parameters of the MPC operation.

\begin{tabular}{|c|c|}
\hline$H \in \mathbb{N}$ & Horizon in delta time slots \\
\hline$\delta \in \mathbb{N}$ & Delta time in seconds \\
\hline$P V_{t} \in \mathbb{R}, t=0 \ldots H$ & Photovoltaic energy \\
\hline Tout $_{t} \in \mathbb{R}, \mathrm{t}=0 \ldots \mathrm{H}$ & Environment temperature \\
\hline $\operatorname{dem}_{t} \in \mathbb{R}, \mathrm{t}=0 \ldots \mathrm{H}$ & Thermal energy demand \\
\hline MaxDem $=\max _{t \in\{0 \ldots H\}}\left(\operatorname{dem}_{t}\right)$ & Maximum energy demand \\
\hline $\operatorname{cost}_{\mathrm{t}} \in \mathbb{R}, \mathrm{t}=0 \ldots \mathrm{H}$ & Energy grid cost \\
\hline TkTh $\in \mathbb{R}$ & Tank temperature threshold \\
\hline$U \in \mathbb{R}$ & $\begin{array}{c}\text { Heat transfer coefficient of } \\
\text { the tank }\end{array}$ \\
\hline$A \in \mathbb{R}$ & $\begin{array}{l}\text { Heat transfer area to the } \\
\text { environment of the tank }\end{array}$ \\
\hline$\varepsilon \in \mathbb{R}$ & $\begin{array}{c}\text { Charging and discharging } \\
\text { efficiency. }\end{array}$ \\
\hline $\mathrm{t} \in \mathbb{R}$ & Operation time \\
\hline$V \in \mathbb{R}$ & Tank volume \\
\hline $\mathrm{C}_{\mathrm{p}} \in \mathbb{R}$ & Specific heat of the water \\
\hline
\end{tabular}

Table 9: Variables of the MPC operation.

\begin{tabular}{|c|c|}
\hline ActPV $_{\mathrm{t}} \in\{0,1\}, \mathrm{t}=0 \ldots \mathrm{H}$ & ON/OFF PV panels \\
\hline ActWT $\in\{0,1\}, \mathrm{t}=0 \ldots \mathrm{H}$ & $\begin{array}{c}\text { ON/OFF energy from the TES } \\
\text { tank }\end{array}$ \\
\hline DemFromHP $_{\mathrm{t}} \in \mathbb{R}$ & $\begin{array}{c}\text { Thermal energy required to } \\
\text { the heat pump for demand }\end{array}$ \\
\hline DemFromWT $_{\mathrm{t}} \in \mathbb{R}$ & $\begin{array}{c}\text { Thermal energy required to } \\
\text { the TES tank for demand }\end{array}$ \\
\hline HPtoWT $_{\mathrm{t}} \in \mathbb{R}$ & $\begin{array}{c}\text { Thermal energy provided to } \\
\text { the TES tank from the HP }\end{array}$ \\
\hline FromGrid $_{\mathrm{t}} \in \mathbb{R}$ & $\begin{array}{c}\text { Electrical energy required to } \\
\text { the grid }\end{array}$ \\
\hline FromPV $_{\mathrm{t}} \in \mathbb{R}$ & $\begin{array}{c}\text { Electrical energy required to } \\
\text { the PV panels }\end{array}$ \\
\hline FromHP $_{\mathrm{t}} \in \mathbb{R}$ & $\begin{array}{c}\text { Electrical energy required to } \\
\text { the HP }\end{array}$ \\
\hline $\mathrm{TkT}_{\mathrm{t}} \in \mathbb{R}$ & Tank temperature \\
\hline
\end{tabular}

Moreover, the constraints of the problem are exposed below:
1. $0 \leq$ DemFromHP $_{\mathrm{t}} \leq$ MaxDem, $\forall \mathrm{t}=0 \ldots \mathrm{H}$
2. $0 \leq$ DemFromWT $_{\mathrm{t}} \leq$ MaxDem, $\forall \mathrm{t}=0 \ldots \mathrm{H}$
3. demand $_{t}=$ DemFromHP $_{t}+$ DemFromWT $_{t} \cdot$ ActWT $_{t}$, $\forall \mathrm{t}=0 \ldots \mathrm{H}$
4. $\mathrm{HPtoWT}_{\mathrm{t}} \geq 0, \forall \mathrm{t}=0 \ldots \mathrm{H}$
5. FromPV $V_{t}=p_{t} \cdot A_{c t P V}, \forall t=0 \ldots H$
6. $0 \leq$ FromHP $_{\mathrm{t}} \leq \mathrm{MaxHP}, \mathrm{Vt}=0 \ldots \mathrm{H}$

7. $\mathrm{COP}_{\mathrm{t}}=0.0005 \cdot$ Tout $_{\mathrm{t}}{ }^{2}+0.0756 \cdot$ Tout $_{\mathrm{t}}+2.2216$, $\forall \mathrm{t}=0 \ldots \mathrm{H}$

8. FromHP Fr $_{t}=\left(\right.$ FromPV $_{t}+$ FromGrid $\left._{t}\right) \cdot \mathrm{COP}_{t}$, thermal energy produced through the heat pump using electrical energy

9. FromHP $_{t}=$ DemFromHP $_{t}+\mathrm{HPoWT}_{\mathrm{t}}, \mathrm{Vt}=0 \ldots \mathrm{H}$.

10. TkT0 $=20^{\circ} \mathrm{C}$, initial temperature of the water tank

11. $\mathrm{TT}_{\mathrm{t}}=\mathrm{TT}_{\mathrm{t}-1}-$ $\ldots \frac{\mathrm{U} \cdot \mathrm{A} \cdot\left(\mathrm{TT}_{\mathrm{t}-1}-\mathrm{Tamb}\right)+\left(\mathrm{HPtoWT}_{\mathrm{t}-1}-\text { DemFromWT }_{\mathrm{t}-1}\right) \cdot \varepsilon \cdot \mathrm{t}}{\mathrm{V} \cdot \mathrm{C}_{\mathrm{p}}}$

12. $\left(\right.$ ActWT $\left._{\mathrm{t}}=1\right) \leftrightarrow\left(\mathrm{TT}_{\mathrm{t}} \geq \mathrm{TT}\right.$ thresh $), \forall \mathrm{t}=1 \ldots \mathrm{H}$, ensures that tank operates above the threshold

Finally, the objective function to minimize for the MPC system was exposed in (Eq. 2):

$$
\min \sum_{\mathrm{t} \in\{0 \ldots \mathrm{H}\}} \operatorname{cost}_{\mathrm{t}} \cdot \text { FromGrid }_{\mathrm{t}}
$$

\section{Case studies}

The proposed algorithm was evaluated in different conditions. First, to explore the possibilities of the MPC working with the water TES tank and PV panels, different combinations among horizons and time steps were simulated for one winter week. Table 10 details all the combinations that were run. These MPC settings were analysed to find out feasible optimization conditions for this paper.

Table 10: Combination of the simulated cases.

\begin{tabular}{|c|c|c|}
\hline Variable & Units & Values \\
\hline Horizon & Hours & $6,12,24,36$, and 48 \\
\hline Time steps & Minutes & $15,30,60$, and 120 \\
\hline
\end{tabular}

Moreover, to study the importance of linking a TES tank with PV panels in a system managed through a MPC strategy, different discharging modes were studied. Figure 4 shows a scheme of the water supplying piping with the corresponding valves.

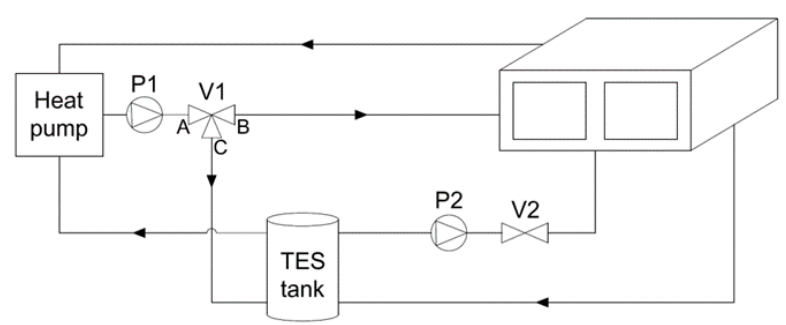

Figure 4: Valves and pumps scheme.

Also, in Table 11 all the operating modes for the valves combinations are detailed. It is worth to remark that the TES tank might not be charged and discharged at the same 
time, meaning that there was a relation with the state of the A-C in V1 and V2 valves. So, when one of them was opened the other was closed.

Table 11: Operating modes.

\begin{tabular}{|c|c|c|}
\hline Mode & Valve V1 & Valve V2 \\
\hline $\begin{array}{c}\text { M1 - Heating and } \\
\text { charging }\end{array}$ & Open A-B and A-C & Closed \\
\hline $\begin{array}{c}\text { M2 - Heating and } \\
\text { discharging }\end{array}$ & Open A-B / Closed A-C & Open \\
\hline $\begin{array}{c}\text { M3 - Heating } \\
\text { only }\end{array}$ & Open A-B / Closed A-C & Closed \\
\hline $\begin{array}{c}\text { M4 - Charging } \\
\text { only }\end{array}$ & $\begin{array}{c}\text { Closed A-B / Open A-C } \\
\text { Closed }\end{array}$ \\
\hline $\begin{array}{c}\text { M5 - Discharging } \\
\text { only }\end{array}$ & Closed A-B and A-C & Open \\
\hline
\end{tabular}

Lastly, it is worth to mention that the main purpose of the work was to study the behaviour of MPC in a heating system with TES and PV panels from an economic savings potential point of view. In order to carry out the study, simpler models of the equipment are required. Otherwise, the computational effort becomes infeasible due to non-linearities in the system.

\section{Results and discussion}

The selected MPC settings for this study were a time step of 60 minutes and a prediction horizon of 24 hours. The computations using shorter time steps needed a lot of time to optimize the final cost. Moreover, regarding to the horizon, simulations with longer horizons than 24 hours did not improve the final economic savings.

Taking into account the aforementioned configuration of the MPC boundary conditions a further study of linking a TES tank with PV panels managed through a MPC strategy was done. The final heating energy cost for the whole winter is shown in Table 12 for all the possible combinations available in the studied system.

Table 12: Final cost in function of the operating mode.

\begin{tabular}{|c|c|c|}
\hline Configuration & Horizon [hours] & Cost [€] \\
\hline NO PV + NO TES & $\mathrm{H}=0$ (NO MPC) & 29.28 \\
\hline PV + NO TES & $\mathrm{H}=0$ (NO MPC) & 27.49 \\
\hline NO PV + TES & $\mathrm{H}=12$ & 26.70 \\
\hline NO PV + TES & $\mathrm{H}=24$ & 25.02 \\
\hline PV + TES & $\mathrm{H}=24$ & 12.27 \\
\hline
\end{tabular}

It is important to highlight that the system without PV panels was able to reduce more than $15 \%$ the total cost just by using the MPC strategy (24 hours of operating horizon) as a manager of the system with the support of a TES tank. In the case with PV panels, but without any TES system or any smart control strategy, the final cost was reduced nearly 6\%.

Also, it can be noted that with TES, PV panels and the MPC working with a horizon of 24 hours around 56\% savings were achieved compared to the base case $(29.28 €)$.
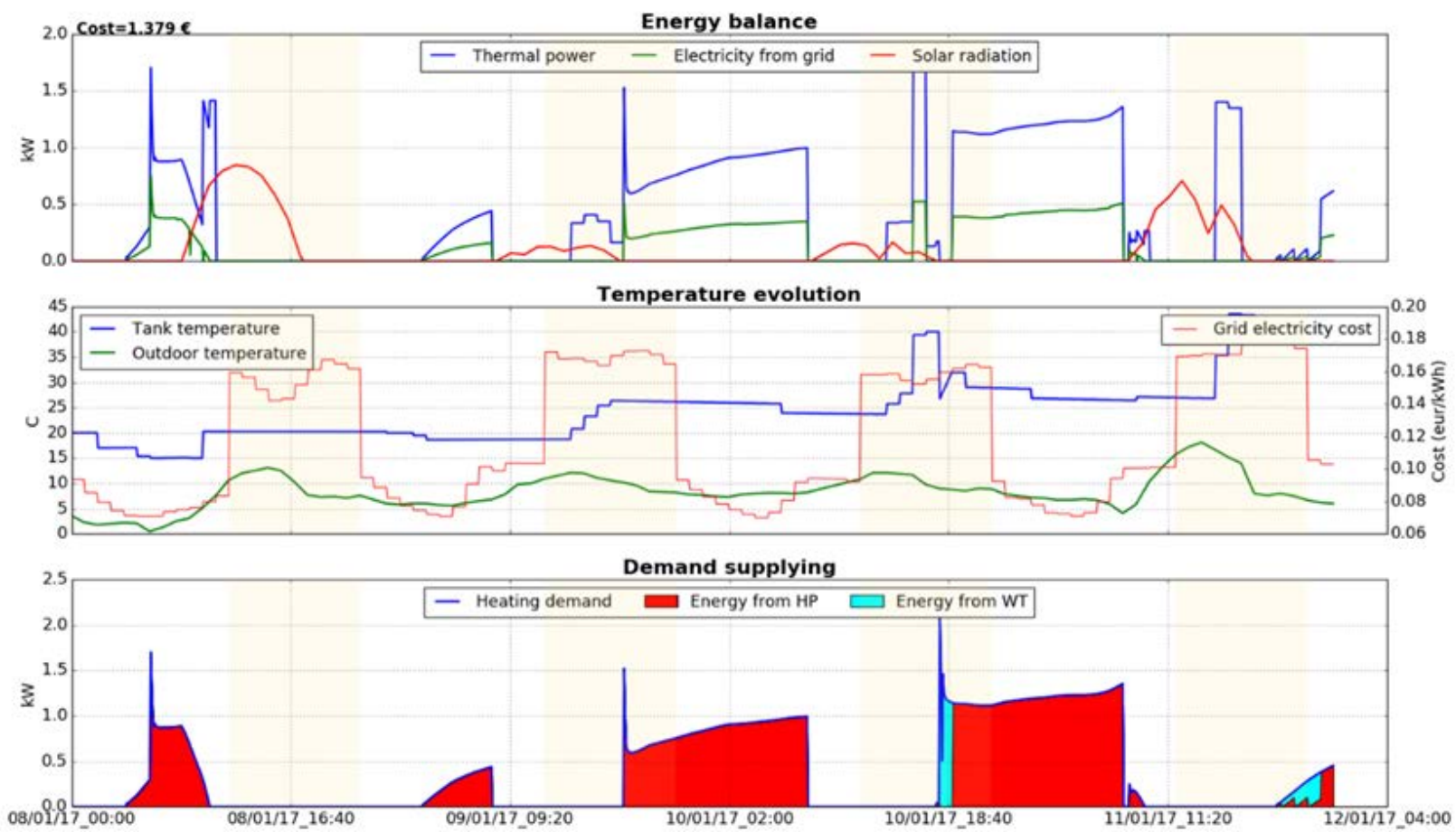

Figure 5: Energy fluxes of four representative winter days with 6 hours of prediction horizon. 

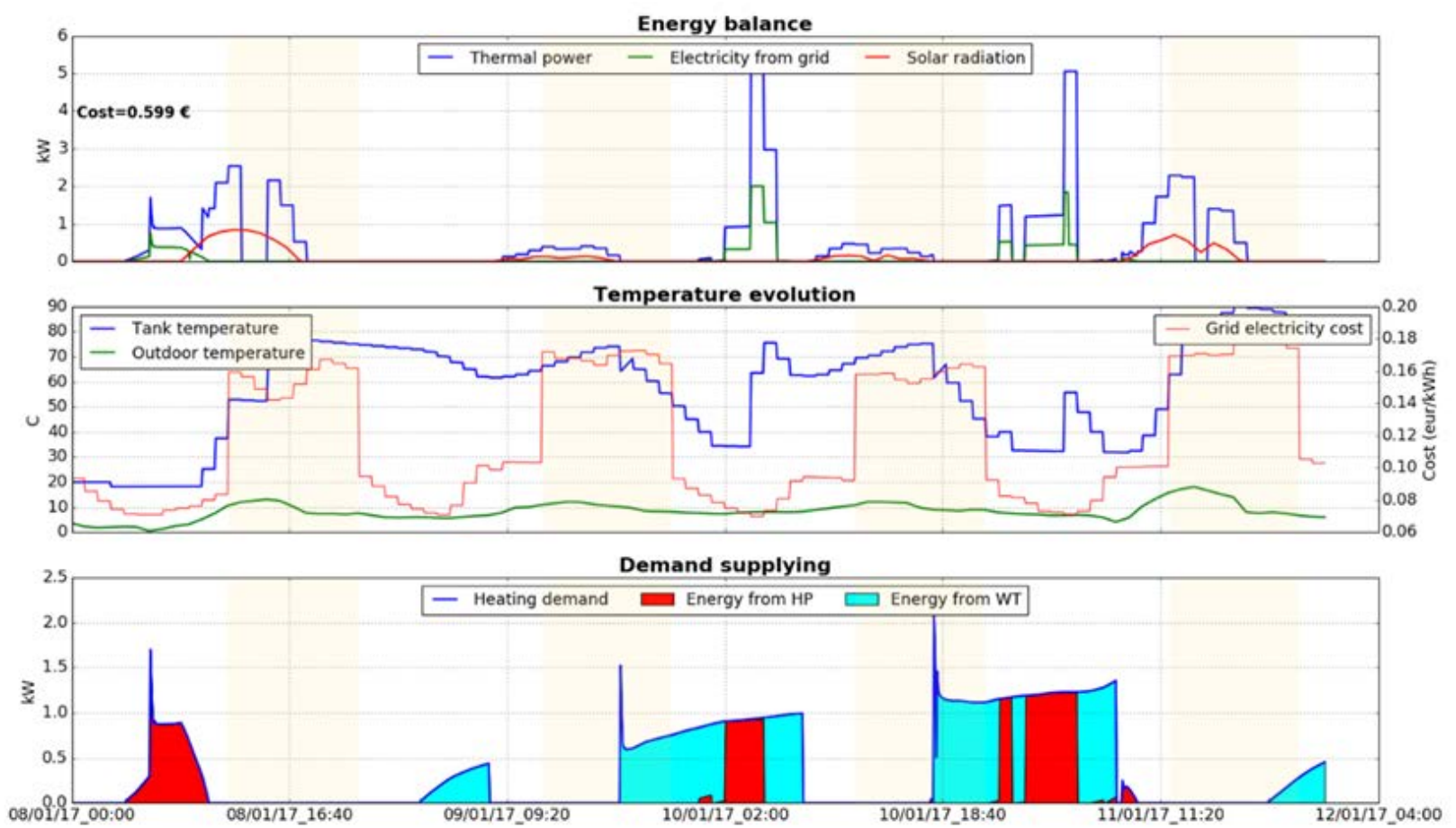

Figure 6: Energy fluxes of four representative winter days with 24 hours of prediction horizon.

Following the high energy savings potential demonstrated by managing a heating operation through a MPC strategy as a decision making tool, four representative winter days were simulated with different horizons (6 and 24 hours) to analyse its impact and how it handled the different inputs and outputs of energy fluxes.

Figure 5 shows three plots. In the first the evolution of the solar radiation and the amount of energy needed from the grid are represented together with the thermal power generated by the HP. That thermal power was determined by the optimizer, considering the heating demand requirement. Further on, the evolution of the tank temperature is shown in the second plot. The outdoor temperature and the grid price are also illustrated. In the case of the electricity cost the on-peak periods are highlighted. Finally, the third plot shows the heating demand required by the user and the energy source used to cover it. As it may be seen in this case, the system worked with a 6 hours prediction horizon and for this reason almost all the demand was fulfilled by the HP. Due to the short horizon, the controller was not able to predict the evolution of the demand in advance and the usefulness of the TES tank and the PV panels became lower. The total heating cost for these four winter days was $1.379 €$.

Otherwise, increasing the prediction horizon until 24 hours the behaviour of the system changed completely. Figure 6 shows the results of the same four days with a horizon of 24 hours. Concerning this case, the cost was $0.599 €$, less than a half compared to the 6 hours optimization.

The main difference between 6 and 24 hours of prediction horizon was the TES tank temperature evolution. It was worked with a different behaviour, due to the capability of the MPC to forecast the future conditions more in advance. Unlike the case presented in Figure 5, the system operation presented in Figure 6 avoided the on-peak zones and reacted against the future disturbances, taking advantage of the solar radiation and the TES tank possibilities. Moreover, it is also worth to note the amount of energy supplied by the HP with the large horizon (red zone in Figure 6) in comparison of the shorter one (red zone in Figure 5).

Focusing on the tank, the simulations started with it fully discharged when using 6 and 24 hours of prediction horizon. The MPC strategy determined to charge and maintain it in a working dead band between $40{ }^{\circ} \mathrm{C}$ and $90{ }^{\circ} \mathrm{C}$ to supply the needed thermal energy to the demand (Figure 6). But, when the prediction horizon was 6 hours, MPC was not able to maintain the TES tank temperature within such working dead band (Figure 5).

\section{Conclusion}

In this study the behaviour of the MPC technology applied to a heating system with PV panels and TES was studied. The algorithm that solves the MPC optimization problem was based on branch-and-bound optimization and it minimized the final energy cost taking into account all the inputs of the system. Such inputs were the heating demand of a single family house, the solar radiation available, the outdoor temperature, which depended on the COP of the air-to-water HP, and the electricity grid price that followed a time-of-use tariff structure.

Regarding to the different operating modes, using PV panels the achieved savings were $6 \%$ compared to the base case without TES, PV and neither MPC. Nevertheless, just the use of MPC and a TES system was able to get a savings of about $15 \%$ for the whole winter heating. 
Moreover, after noting the importance of coupling a MPC strategy with a TES system and PV panels, two different prediction horizons were tested: 6 and 24 hours. The difference in final cost between them was the double, being $56 \%$ savings compared to the base case without any improvement.

Finally, even though the precision in the final results could be improved using more accurate models for all the elements, the reliability of the economic savings potential of a heating system with TES and PV panels managed by a MPC strategy was demonstrated. The presented system was able to reduce the final cost of heating for the whole winter in less than a half, compared against a conventional one.

\section{Acknowledgement}

This work was partially funded by the Ministerio de Economía, Industria y Competitividad de España (ENE2015-64117-C5-1-R (MINECO/FEDER) and ENE2015-64117-C5-3-R (MINECO/FEDER)). This project has received funding from the European Union's Horizon 2020 research and innovation programme under the Marie Sklodowska-Curie grant No 712949 (TECNIOspring PLUS) and from the Agency for Business Competitiveness of the Government of Catalonia. The authors would like to thank the Catalan Government for the quality accreditation given to their research group (2017 SGR 1537). GREiA is certified agent TECNIO in the category of technology developers from the Government of Catalonia.

\section{References}

Achterberg, T. (2009). SCIP: solving constraint integer programs. Mathematical and Programming Society, 1:1-41.

Afram, A. and Janabi-Sharifi, F. (2014). Theory and applications of HVAC control systems - A review of model predictive control (MPC). Building and Environment 72, 343-355.

Alimohammadisagvand, B., Jokisalo, J., Kilpeläinen, S., Ali, M., and Sirén, K. (2016). Cost-optimal thermal energy storage system for a residential building with heat pump heating and demand response control. Applied Energy 174, 275-287.

American Society of Heating, Refrigerating and AirConditioning Engineers (2011). Standard Method of testing for the Evaluation of Building Energy Analysis Computer Programs (Standard 140-2011).

Avci, M., Erkoc, M., Rahmani, A., and Asfour, S. (2013). Model predictive HVAC load control in buildings using real-time electricity pricing. Energy and Buildings 60, 199-209.

Candanedo, JA., Dehkordi, VR., and Stylianou, M. (2013). Model-based predictive control of an ice storage device in a building cooling system. Applied Energy 111, 1032-1045.

Chu, S. and A. Majumdar (2012). Opportunities and challenges for a sustainable energy future. Nature 488, 294-303.

Dincer, I., Midilli, A., Kucuk, H. (2014). Progress in sustainable energy technologies. Vol II.

Gholamibozanjani, G., Tarragona, J., de Gracia, A., Fernández, C., Cabeza, LF., and Farid, MM. (2018). Model predictive control strategy applied to different types of building for space heating. Applied Energy 231, 959-971.

International Energy Agency (2016a). Energy, climate change and environment.

International Energy Agency (2016b). Energy technology perspectives.

International Energy Agency (2016c). World energy outlook.

Oldewurtel, F., Parisio, A., Jones, CN., Gyalistras, D., Gwerder, M., Stauch, V., Lehmann, B., and Morari, M. (2012). Use of model predictive control and weather forecasts for energy efficient building climate control. Energy and Buildings 45, 15-27.

Salakij, S., Yu, N., Paolucci, S., and Antsaklis, P. (2016). Model-Based Predictive Control for building energy management. I: Energy modelling and optimal control. Energy and Buildings 133, 345-358.

Thieblemont, H., Haghighat, F., Ooka, R., and Moreau, A. (2017). Predictive control strategies based on weather forecast in buildings with energy storage system: A review of the state-of-the-art. Energy and Buildings 153, 485-500.

Touretzky, CR. and Baldea, M. (2014). Integrating scheduling and control for economic MPC of buildings with energy storage. Journal of process control, 1291-1300.

Vrettos, E., Lai, K., Oldewurtel, F., \& Andersson, G. (2013). Predictive Control of Buildings for Demand Response with Dynamic Day-ahead and Real-time Prices. European Control Conference (ECC). Zürich (Switzerland), 17-19 July, 2013.

Yu, Z., Huang, G., Haghighat, F., Li, H., and Zhang, G. (2015). Control strategies for integration of thermal energy storage into buildings: State-of-the-art review. Energy and Buildings 106, 203-215. 